\title{
Differentiation of Biologically Distinct Peanut Stripe Potyvirus Strains by a Nucleotide Polymorphism-Based Assay
}

\author{
S. S. Pappu, Department of Entomology, and H. R. Pappu, Department of Plant Pathology, University of Georgia, \\ Coastal Plain Experiment Station, Tifton 31793; C. A. Chang, Taiwan Agricultural Research Institute, Taichung, \\ Taiwan; and A. K. Culbreath, Department of Plant Pathology, and J. W. Todd, Department of Entomology, Uni- \\ versity of Georgia, Coastal Plain Experiment Station, Tifton 31793
}

\begin{abstract}
Pappu, S. S., Pappu, H. R., Chang, C. A., Culbreath, A. K., and Todd, J. W. 1998. Differentiation of biologically distinct peanut stripe potyvirus strains by a nucleotide polymorphism-based assay. Plant Dis. 82:1121-1125.

A necrotic strain of peanut stripe potyvirus (PStV-Ts) was used to design and test strain-differentiating oligonucleotides. The $3^{\prime}$ region of PStV-Ts, including a part of the NIb region, the complete coat protein (CP) gene, and the $3^{\prime}$-untranslated region, was cloned and sequenced. PStV-Ts had a high degree of sequence identity (92 to 95\%) to the known non-necrotic (blotch) strains both at the nucleotide and amino acid sequence levels. Nucleotide sequence differences unique to the necrotic strain were identified when compared to the available non-necrotic isolates of PStV. Nucleotide polymorphism in the CP gene sequences was utilized in designing oligonucleotides that were specific to the necrotic strain, and were employed in an assay to differentiate the necrotic strain from non-necrotic. The 3' end mismatch in the oligonucleotides contributed in particular to the differentiation of the strains. This approach facilitated rapid, sensitive, and reliable detection and differentiation of PStV strains.
\end{abstract}

Additional keywords: capsid gene sequence, necrotic strains, RT-PCR, strain differentiation

Peanut stripe potyvirus (PStV) is one of the major peanut (Arachis hypogaea L.)infecting viruses that adversely impact peanut production in several parts of the world. The virus has become endemic in most peanut-growing countries (7). Several PStV isolates have been described from different countries, and their biological and serological properties have been studied $(4,7,21)$.

Most strains of PStV cause a typical stripe or vein banding pattern (described as "blotch;" PStV-B) on leaves of peanut $(6,7)$. In 1990, PStV strains causing necrosis on peanut were described from Taiwan (4) and Thailand (21). More recently, a necrotic strain of PStV was isolated from peanut and Florida beggar-weed (Desmodium tortuosum (SW.) DC.) in the United States (18). The necrotic strain from Taiwan (PStV-Ts) differs from the other PStV isolates in the severity of symptoms it induces in peanut. It produces necrotic lesions on leaves, with the necrosis later extending to the midribs, petioles, and sometimes to the stems (4). This leads to stunting, severe mosaic, and systemic fo-

Corresponding author: H. R. Pappu

E-mail: hrp@tifton.cpes.peachnet.edu

Accepted for publication 25 June 1998.

Publication no. D-1998-0731-02R

(C) 1998 The American Phytopathological Society liar distortion or stripe symptoms on peanut.

Blotch strains of PStV have become well-established in the peanut belt of the United States, but they do not cause significant yield reduction (12). Regional differences in the impact of PStV may be related to the virulence differences between blotch and necrotic strains. Considering the seed-borne nature of PStV, movement of necrotic strains through infected peanut seed poses a threat to peanutgrowing regions where necrotic strains are not present. Polyclonal antisera are unable to distinguish PStV-Ts from less severe strains of PStV. A monoclonal antibody (MAb) specific to PStV was developed (5). In direct antigen coated-enzyme-linked immunosorbent assay, this MAb did not react with $\mathrm{PStV}$-Ts and also failed to react with certain blotch isolates from Georgia (I. B. Bhat and H. R. Pappu, unpublished). Detection and differentiation of necrotic strains of PStV from non-necrotic strains would help disease management programs. Thus, availability of rapid and reliable methodology is essential to monitor, identify, and restrict the introduction or movement of potentially more aggressive strains of PStV into new locations. Strain-specific primers and their use in a polymerase chain reaction (PCR)-based assay would be a valuable tool in achieving this objective.

Toward this goal, the $3^{\prime}$ terminal 1356 nucleotides of the PStV-Ts genomic RNA was cloned and sequenced. The sequence differences between PStV-Ts and the blotch strains were utilized to design and test oligonucleotides for strain differentiation.

\section{MATERIALS AND METHODS}

PStV strains. The blotch isolate of PStV (PStV-B) was reported from Georgia (6). The necrotic strain of PStV (PStV-Ts) studied was characterized by Chang et al. (4) because the necrotic isolate from Georgia (18) could not be recovered from desiccated tissue.

Preparation of tissue extracts for reverse transcriptase-PCR, cloning, and sequence analysis. Both isolates were maintained, after single lesion transfers from peanut, on Vigna unguiculata cv. Blackeye or Nicotiana tabacum. Desiccated tissue was used for extracting total nucleic acids as described previously (14). Amplification of the $3^{\prime}$ region of the PStVTs viral genome was done by reverse transcription (RT)-PCR using a Perkin-Elmer thermal cycler (GeneAmp model 2400; Perkin-Elmer Corp., Norwalk, CT) as described (14). Degenerate primers that would amplify the 3 '-terminal region consisting of a part of the $\mathrm{NIb}$, the complete coat protein (CP) gene, and the 3 '-untranslated region (UTR) were described in Pappu et al. (15). The resulting PCR product was cloned into a pGEM-T vector (Promega Corp., Madison, WI). Recombinant clones were identified by using standard molecular biological procedures (17). Nucleotide sequences of the recombinant clones were obtained using an automated sequencer (DNA Sequencing Core Facility, Interdisciplinary Center for Biotechnology Research, University of Florida, Gainesville). Sequence analyses were done using Seqaid-II (16), programs of the University of Wisconsin Genetics Computer Group (8), and CLUSTALW (20). Sequence searches of the GenBank database (2) were done by using BLAST program (1).

Strain-differentiating PCR. Oligonucleotides with a $3^{\prime}$ mismatch were synthesized for each of the $\mathrm{CP}$ genes of blotch and necrotic strains. A cloned DNA preparation of PStV-Ts was used in PCR. Reaction conditions used were as follows: 30 cycles of amplification with denaturation at $90^{\circ} \mathrm{C}$ for $30 \mathrm{~s}$, annealing at $58^{\circ} \mathrm{C}$ for $30 \mathrm{~s}$, and extension at $72^{\circ} \mathrm{C}$ for $30 \mathrm{~s}$. For PStV- 
B, a tissue extract was used in RT-PCR. Amplification conditions were the same as those used for PStV-Ts, except for an additional RT step for $45 \mathrm{~min}$ at $42^{\circ} \mathrm{C}$ prior to
PCR. Oligonucleotides representing the same region in the $\mathrm{CP}$ gene, but having no mismatches, were used as positive controls for each strain.
RESULTS AND DISCUSSION

Sequence analyses of the $3^{\prime}$ region of PStV-Ts. The nucleotide and predicted amino acid sequences of the 3' 1356-base

ATGATTGAAGCATGGGGCTATCCTGAATTGCTCCAAGAAATTAGGAAATTTTACTTGTGGCTGCTTGAGA 
pair (bp) region are presented in Figure 1. The sequenced region consisted of a 1104bp open-reading frame potentially coding for a peptide sequence, 367 amino acids long, of the polyprotein. The sequence has been submitted to the GenBank under accession number AF063222.
The protease cleavage site for the capsid protein was predicted to be between the residues glutamine and serine (Fig. 1). The aphid-transmissibility of this strain was in agreement with the presence of the amino acid triplet DAG (4). The CP was presumed to be 287 residues long and was the same length as the blotch strains described (Fig. 2A). The necrotic strain had a high level of sequence identity at the $\mathrm{CP}$ amino acid level to the blotch strains. The $\mathrm{CP}$ amino acid sequence identity was 95 and 96\% with PStV-B $(9,10)$ and PStV-IB (19), respectively (Fig. 2A). Sequence diver-

\section{A}

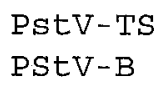

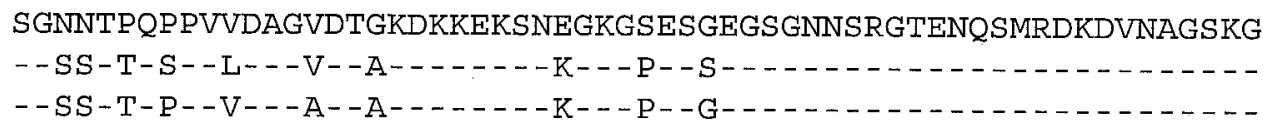

Fig. 2. Comparative alignment of the peanut stripe potyvirus (PStV)-Ts isolate's (A) coat protein sequence and (B) nucleotide sequence of the $3^{\prime}$-untranslated region with those of blotch strains of PStV from Georgia (PStV-B) and Indonesia (PStV-IB). A dash indicates identical residues at that position in all three strains. $\mathrm{X}$ indicates a gap. Alignments were generated using the CLUSTALW program (20). 
gence was more pronounced at the amino terminal end of the CP (Fig. 2A). The 3'UTR was 252 nucleotides long (Fig. 1), two nucleotides less than the PStV-B and the same length as that of PStV-IB (Fig. 2B). The nucleotide sequence identity of the $3^{\prime}$-UTR was $92 \%$ between PStV-Ts and PStV-B and 94\% between PStV-Ts and PStV-IB.

While PStV-Ts was highly identical to the blotch strains (B and IB) in both CP gene and 3'-UTR sequences, differences at both nucleotide and amino acid levels were noticed. There were six positions within the first 31 amino acid residues where both PStV-B and PStV-IB differed from PStVTs (Fig. 2A). Similarly, while the 3'-UTR sequences of PStV-Ts and the blotch strains were highly identical, sequence differences were observed (Fig. 2B).

Strain differentiation by PCR. Primers that were specific to either of the blotch strains (B and IB) or to the necrotic strain (Ts) of PStV were designed based on their respective $\mathrm{CP}$ gene sequences (Table 1). A schematic of the procedure is given in Figure 3. In each case, a differentiating oligonucleotide was used as the "forward" primer for PCR in combination with a nondifferentiating "reverse" primer. The oligonucleotide pair HRP39-HRP19, derived from the $\mathrm{CP}$ gene, was a perfect match for PStV-Ts (Fig. 3A). For PStV-B, HRP39 was the differentiating primer and HRP19 was the non-differentiating primer. The locations of the primers HRP39 and HRP19 are indicated in Figure 1. Likewise, the primer pair HRP40-HRP41 was a perfect match for PStV-B and IB (Fig. 3B), with HRP40 being the differentiating primer for PStV-Ts and HRP41 the nondifferentiating primer. Oligonucleotide HRP39 was longer than the oligonucleotide HRP40 at the $5^{\prime}$ end by two nucleotides (Table 1). This length difference was necessary to keep the melting temperatures of HRP 39 and HRP40 similar. The difference in the two upstream primers was not significant because the two extra nucleotides in HRP39 were conserved in the blotch strains (PStV-B and PStV-IB). There were three positions where PStV-B and PStV-IB (or the corresponding oligonucleotide HRP40) differ from the oligonucleotide HRP39 (Fig. 3) and only one position where they (or the corresponding oligonucleotide HRP41) differ from the oligonucleotide HRP19. The one-base difference between HRP19 and the CP gene sequence of blotch strains is not sufficient to discriminate between PStV-Ts and the blotch strains under the amplifica-

Table 1. Oligonucleotides used in reverse transcription-polymerase chain reaction of peanut stripe potyvirus strains. The lower case letters in the primer sequences indicate mismatches between HRP39 and the corresponding primer, HRP40; between HRP19 and the corresponding primer, HRP41.

\begin{tabular}{llll}
\hline Oligomer & \multicolumn{1}{c}{ Sequence $\left(\mathbf{5}^{\prime}\right.$ to $\left.\mathbf{3}^{\prime}\right)$} & Strain & Orientation \\
\hline HRP39 & caT CTA CAa TCA GGG AaC Aa & PStV-Ts & Sense \\
HRP40 & TCT ACA gTC AGG GAg CAg & PStV-B & Sense \\
HRP41 & CCA TCA TCA CCC ATG TtC C & PStV-B & Antisense \\
HRP19 & CCA TCA TCA CCC ATG TaC C & PstV-Ts & Antisense \\
\hline
\end{tabular}

y Orientation with respect to genomic RNA.

z The two extra nucleotides at the 5'-end of HRP39 are explained in the text (see "Results").

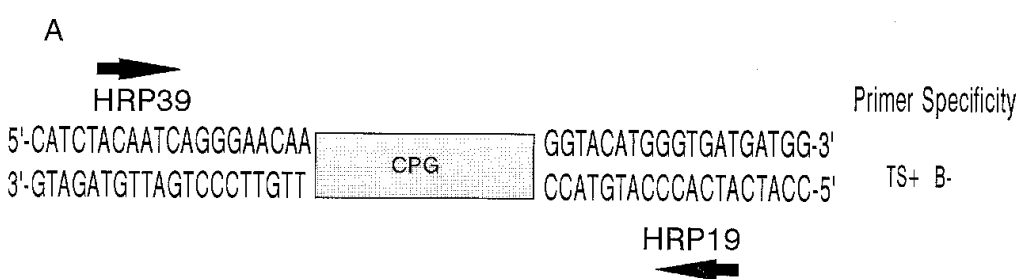

$\mathrm{B}$

HRP40

TS. B+

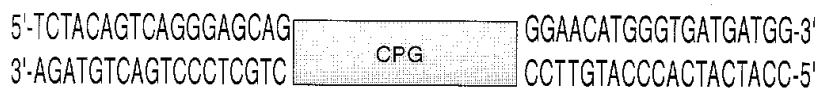

HRP41

Fig. 3. Schematic showing a polymerase chain reaction-based assay for differentiating peanut stripe potyvirus (PStV)-Ts isolate from the non-necrotic strains used in this study. (A) Using a primer that is specific to PStV-Ts (HRP39) would result in a 472 base pair (bp) polymerase chain reaction (PCR) product, while this primer would not give a PCR product when used with a non-necrotic strain, due to the mismatch in the $3^{\prime}$ end of the primer. (B) Similarly, the primer specific to the non-necrotic strain (HRP40) would give a 472 bp PCR product, while not recognizing the necrotic strain. Arrowheads indicate the orientation of the primers. tion conditions used in this study (data not shown). Hence, HRP19 was considered to be a non-differentiating primer for PStV-B and PStV-IB. The same situation applies for HRP41, the non-differentiating primer for PStV-Ts.

The r'esults of the strain differentiationPCR reaction are presented in Figure 4. The primer pair HRP39-HRP19 produced a product of expected size with the PStV-Ts template (Fig. 4, lane 2) but not with the PStV-B template (Fig. 4, lane 3). Similarly, the primer pair HRP40-HRP41 resulted in a product of expected size with the PStV-B template (Fig. 4, lane 5), but not with the PStV-Ts template (Fig. 4, lane 4).

These results demonstrate the utility of sequence information and sequence differences in developing a sensitive and rapid approach for differentiating strains of PStV. Traditional methods to identify PStV strains include biological assays involving selected indicator plants. While this approach is still valuable, it is costly and requires considerable amount of time and greenhouse space. Use of PCR has been widely applied for the rapid detection of viruses and viroids (11). Strain-specific primers were used in PCR and nucleic acid hybridization techniques for strain differentiation of citrus tristeza closterovirus (3) and soybean mosaic potyvirus (13). The inability of native Taq DNA polymerase to correct mismatches between the template DNA and the $3^{\prime}$ end of the primer was utilized in developing strain-specific primers for necrotic (PStV-Ts) and non-necrotic (PStV-B and PStV-IB) isolates of PStV. Using peanut plants doubly infected with

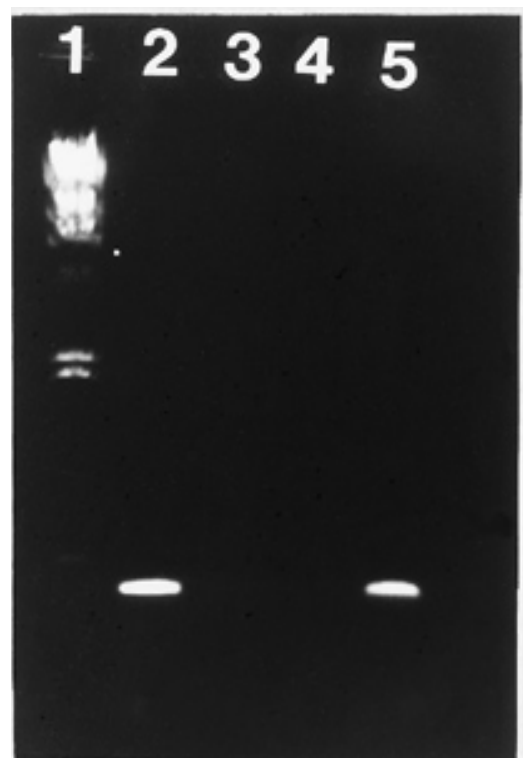

Fig. 4. Agarose gel $(0.8 \%)$ electrophoresis of polymerase chain reaction products. Lane 1 , Lambda DNA digested with HindIII; lane 2, peanut stripe potyvirus (PStV)-Ts template with HRP39-HRP19 primer pair; lane 3, PStV-B template with HRP39-HRP19; lane 4, PStV-Ts with HRP40-HRP41; lane 5, PStV-B with HRP40-HRP41. 
both PStV-B and PStV-Ts, individual primer pairs specific to each of the strains could differentiate the mixed infection (not shown). Comparison of PStV sequences available in GenBank (2) showed that the primer HRP39 was unique to PStV-Ts and thus could distinguish it from known PStV strains. Considering the seed-borne nature of PStV, this technique has a potential application in quarantine programs for screening imported seed material and germplasm.

\section{ACKNOWLEDGMENTS}

We thank B. Cassidy for providing PStV-B and for many helpful discussions; J. Sherwood for supplying PStV-specific monoclonal antibody 3AB5; $\mathrm{K}$. Lewis and W. Tillery for technical assistance; and the Research Computing Resource Facility, University of Georgia, Athens, for providing access to sequence analyses programs.

\section{LITERATURE CITED}

1. Altschul, S. F., Gish, W., Miller, W., Myers, E. W., and Lipman, D. J. 1990. Basic local alignment search tool. J. Mol. Biol. 215:403410 .

2. Benson, D. A., Boguski, M., Lipman, D. J., and Ostell, J. 1996. GenBank. Nucleic Acids Res. 24:1-5.

3. Cevik, B., Pappu, S. S., Pappu, H. R., Benscher, D., Irey, M., Lee, R. F., and Niblett, C. L. 1995. Application of bi-directional PCR to citrus tristeza virus: Detection and strain differentiation. Pages 17-24. In: Proc. XIII Conf. Int. Org. Citrus Virol. J. da Graca, P. Moreno, and R K Yokomi, eds. University of California, Riverside.

4. Chang, C. A., Purcifull, D. E., and Zettler, F. W. 1990. Comparison of two strains of peanut stripe virus in Taiwan. Plant Dis. 74:593-596.

5. Culver, J., and Sherwood, J. L. 1988. Detection of peanut stripe virus in peanut seed by an indirect enzyme-linked immunosorbent assay using a monoclonal antibody. Plant Dis. 72:676-679.

6. Demski, J. W., Reddy, D. V. R., Sowell, G., and Bays, D. 1984. Peanut stripe virus-a new seed-borne potyvirus from China infecting groundnut (Arachis hypogaea). Ann. Appl. Biol. 105:495-501.

7. Demski, J. W., Reddy, D. V. R., Wongkaew, S., Xu, Z. Y., Kuhn, C. W., Cassidy, B. G., Shukla, D. D., Saleh, N., Middleton, K. J., Sreenivasulu, P., Prasada Rao, R. D. V. J., Senboku, T., Dollet, M., and McDonald, D. 1993. Peanut stripe virus. Inf. Bull. No. 38, Peanut Collaborative Res. Support Prog. (Peanut CRSP) University of Georgia, Griffin 30223 and International Crops Research Institute for the Semi-Arid Tropics (ICRISAT) Patancheru, Andhra Pradesh 502324, India.

8. Devereux, J., Haeberli, P., and Smithies, O. 1984. A comprehensive set of sequence analysis programs for the VAX. Nucleic Acids Res. 12:387-395.

9. Flasinski, S., Gunasinghe, U. B., Gonzales, R. A., and Cassidy, B. G. 1996. The cDNA sequence and infectious transcripts of peanut stripe virus. Gene 171:299-300.

10. Gunasinghe, U. B., Flasinski, S., Nelson, R. S., and Cassidy, B. G. 1994. Nucleotide sequence and genome organization of peanut stripe potyvirus. J. Gen. Virol. 75:25192526.

11. Hadidi, A., Levy, L., and Podleckis, E. V. 1995. Polymerase chain reaction technology in plant pathology. Pages 167-187 in: Molecular Methods in Plant Pathology. R. P. Singh and U. S. Singh, eds. CRC Press, Boca Raton, FL.

12. Lynch, R. E., Demski, J. W., Branch, W. D., Holbrook, C. C., and Morgan, L. W. 1988. Influence of peanut stripe virus on growth, yield, and quality of Florunner peanut. Peanut Sci. 15:47-52.

13. Omunyin, M. E., Hill, J. H., and Miller, W. A. 1996. Use of unique RNA sequence-specific oligonucleotide primers for RT-PCR to detect and differentiate soybean mosaic virus strains. Plant Dis. 80:1170-1174.

14. Pappu, S. S., Brand, R., Pappu, H. R., Rybicki, E. P., Gough, K. H., Frenkel, M. J., and Niblett, C. L. 1993. A polymerase chain reaction method adapted for selective amplification and cloning of 3' sequences of potyviral genomes: Application to dasheen mosaic virus. J. Virol. Methods 41:9-20.

15. Pappu, H. R., Pappu, S. S., and Sreenivasulu, P. 1997. Molecular characterization and interviral homologies of a potyvirus infecting sesame (Sesamum indicum) in Georgia. Arch Virol. 142:1919-1927.

16. Rhoads, D. D., and Roufa, D. S. 1985. Emetine resistance of Chinese hamster cells: structure of wild type and mutant ribosomal protein S14 messenger RNA species. Mol. Cell. Biol. 5:1655-1659.

17. Sambrook, J., Fritsch, E. F., and Maniatis, T. 1989. Molecular Cloning: A Laboratory Manual. Cold Spring Harbor Laboratory, New York.

18. Sreenivasulu, P., Demski, J. W., Kuhn, C. W., and Christie, R. G. 1992. Characterization of a necrosis strain of peanut stripe virus infecting beggarweed and groundnut in Georgia Int. Arachis Newsl. 11:21-23.

19. Teycheney, P. Y., Young, P., and Dietzen, R. G. 1994. Cloning and sequence analysis of the coat protein gene of an Australian strain of peanut mottle and an Indonesian "blotch" strain of peanut stripe potyviruses. Virus Res. 31:235-244.

20. Thompson, J. D., Higgins, D. G., and Gibson, T. J. 1994. CLUSTAL W: Improving the sensitivity of progressive multiple sequence alignment through sequence weighting, positions-specific gap penalties and weight matrix choice. Nucleic Acids Res. 22:4673-4680.

21. Wongkaew, S., and Dollet, M. 1990. Comparison of peanut stripe virus isolates using symptomatology on particular hosts and serology. Oleagineux 45:267-278 